\title{
HUBUNGAN IKLIM KERJA DAN TEKNOLOGI PEMBELAJARAN DENGAN KUALITAS PEMBELAJARAN GEOGRAFI PADA SMA NEGERI DI PALANGKA RAYA
}

\author{
Relationship between Work Climate and Learning Technology with the Quality of \\ Geography Learning at State High Schools in Palangka Raya
}

\section{Sutya Devi \\ Teguh Pribadi* \\ Elyta Vivi Yanti}

Sriyana

Universitas PGRI Palangka Raya,

Palangka Raya, Central

Kalimantan, Indonesia

*email: tgpribadi@gmail.com

\section{Kata Kunci:}

Guru Geografi

Kualitas Pembelajaran

Teknologi Pembelajaran

SMA Negeri

Iklim Kerja

\section{Keywords:}

Geography teacher

Quality of learning

Learning technologies

Public Senior High School

School Climate

Accepted

February 2019

\section{Published}

June 2019

\begin{abstract}
Abstrak
Guru merupakan komponen penting pendidikan sekaligus penentu kualitas pendidikan. Profesionalisme guru ditandai dengan peningkatan kualitas pembelajaran (KP) melalui pemanfaatan dan pengoptimalan teknologi pembelajaran (TP). Di samping itu, KP juga didukung oleh kondisi iklim kerja (IK) yang kondusif di sekolah. Penelitian ini melaporkan hasil penelitian yang menyelidiki hubungan antara IK guru dan pemanfaatan teknologi pembelajaran (PTP) dengan KP. Enam belas partisipan yang berasal dari guru-guru mata pelajaran geografi di SMA Negeri (SMAN) di Palangka Raya yang telah memberikan tanggapan terhadap angket dan mencatat persepsi mereka tentang IK di sekolah, PTP, dan KP. Korelasi Spearman yang digunakan untuk menguji hubungan IK dan PTP terhadap KP guru-guru geografi SMAN di Palangka Raya. Hasil dari penelitian ini menunjukkan bahwa hanya PTP dengan KP yang memiliki hubungan positif dan bermakna. Sedangkan untuk IK tidak memberikan pengaruh pada KP geografi pada SMAN di Palangka Raya. Implikasi penelitian ini adalah peningkatan KP dapat dilakukan dengan meningkatkan kemampuan guru dalam menggunakan TP dan memanfaatkannya dalam kegiatan belajar mengajar di kelas.
\end{abstract}

\begin{abstract}
Teachers are an essential component of education as well as a determinant of the quality of education. The Teacher's professionalism is characterized by improving the learning quality (LQ) through the utilization and optimization of learning technology. Also, the quality of teaching is also supported by a conducive working environment conditions at the school. This study reported the results of research which investigated the correlation between school climate (SC) and learning technology utilization (LTU) with LQ. Sixteen participants from geographic subject teachers at the State Senior High School (PSHS) in Palangka Raya have responded to the questionnaire and recorded their perceptions of SC, LTU, and LQ. Spearman correlation analysis was used to test their correlation. This study revealed a positive relationship between $L T U$ and LQ. As for the SC did not give influence on the $L Q$ at PSHS in Palangka Raya. So that improving the $L Q$ can be done by enhancing the ability of teachers in LTU and use it in teaching and learning activities in the classroom..
\end{abstract}

\section{PENDAHULUAN}

Guru sebagai manusia dewasa sadar dan bertanggung jawab untuk mendidik, mengajar, dan membimbing peserta didik. Salah satu tugas guru yaitu menyampaikan pengetahuan atau pengalaman yang dimiliki kepada siswa sehingga agar mengerti dan memahami pesan yang disampaikan oleh guru. Guru juga berperan dalam membantu dan mendampingi perkembangan peserta didik dalam rangka pencapaian tujuan hidup secara optimal. Guru berperan penting dalam pengembangan sumber daya manusia yang berkualitas dalam pembangunan bangsa. Oleh karena itu, guru merupakan komponen penting dalam proses belajar-mengajar dan penentu kualitas pendidikan (KP), selain mutu sekolahan 
dan manajemen pendidikan (Esi et al., 2016; Suniati, 2014).

Iklim kerja (IK) yang kondusif akan memberikan peluang dan menumbuhkan kreativitas dan inovasi dari para anggota organisasi untuk berinovasi lebih, bebas untuk mencari cara-cara baru dalam menyelesaikan suatu pekerjaan. IK guru juga harus di perhatikan sebagai salah satu indikator dalam peningkatan kualitas guru. IK sekolah tempat guru melakukan tugas meliputi lingkungan fisik, sosial, intelektual, dan nilai-nilai. Kondisi lingkungan ini akan mempengaruhi perilaku warga sekolah dalam melaksanakan tugas dan tanggung jawabnya (Munfarijah, 20I5).

Kemajuan teknologi memberikan beragam penawaran dan pilihan paket media pembelajaran untuk mendukung proses pembelajaran yang lebih efektif dan efisien. Keuntungan yang ditawarkan oleh kemajuan teknologi berupa kecepatan dan beragam informasi tetapi juga fasilitas multimedia yang dapat membuat proses belajar menjadi lebih menarik, visual, dan interaktif. Teknologi pendidikan (TP) terkait aplikasi pengetahuan berbasiskan ilmu pengetahuan ke dalam proses pendidikan. TP dapat menciptakan suatu pembelajaran yang berkualitas. Kualitas pembelajaran dapat diartikan sebagai intensitas keterkaitan sistemik dan sinergis guru, siswa, kurikulum, bahan belajar, media, fasilitas dan sistem pembelajaran dalam menghasilkan proses serta hasil belajar yang optimal (Nurbudiyani et al., 2013; Triyanto et al., 2013).

Kualitas pembelajaran (KP) merupakan tingkat keberhasilan kegiatan belajar-mengajar yang berjalan secara sistematik dan sinergis antara guru, siswa, kurikulum, bahan ajar, media, fasilitas, dan sistem pembelajaran sesuai dengan tuntunan kurikulum. KP di sekolahan ditentukan oleh beberapa komponen, antara lain: I) keterampilan guru dalam menyampaikan pembelajaran; 2) aktivitas siswa dalam kegiatan belajar mengajar; 3) hasil belajar siswa; 4) metode pembelajaran yang digunakan; 5) media pembelajaran yang digunakan;
6) materi pembelajaran; dan 7) iklim atau suasana belajar (Rohmawati, 20I5).

Agar proses pembelajaran berjalan dengan baik, maka guru perlu mendayagunakan berbagai disiplin ilmu pendidikan, di antaranya penerapan teknologi pendidikan dalam sistem pembelajaran. Penerapan teknologi pembelajaran merupakan salah satu cara yang dapat di lakukan untuk mengatasi kelemahan pendidikan selama ini yang di lakukan secara klasikal. Penggunaan teknologi dalam pembelajaran bukan hanya dapat menunjang kreativitas siswa, tetapi juga dapat menunjang ke kualitas guru dalam pengajaran (Anshori, 2017). Namun demikian, penelitian tentang hubungan antara IK dan pemanfaatan teknologi pembelajaran (PTP) dengan KP di Palangka Raya, khususnya pembelajaran geografi di SMA belum dilakukan. Oleh karena itu penelitian ini bertujuan mengukur hubungan dan kebermaknaan I) IK dengan KP; dan 2) PTP dengan KP yang dilakukan oleh guru-guru geografi pada SMAN di Kota Palangka Raya.

\section{METODOLOGI}

Enam belas guru mata pelajaran geografi dari delapan SMAN di Palangka Raya dipilih secara purposif dan ditetapkan sebagai partisipan penelitian ini. Penyebaran angket dan wawancara dilakukan dari Bulan Juli sampai Bulan September 2015. Delapan dari sepuluh SMAN di Palangka Raya dipilih berdasarkan keberadaan guru mata pelajaran geografi dan aksesibilitas.

Profil partisipan penelitian ini didominasi oleh guru yang berumur $>45$ tahun atau guru senior ( $>60 \%$ atau 10:16). Guru laki-laki dan perempuan memiliki jumlah yang berimbang (8:8). Tiga guru yang menjadi partisipan sudah menyelesaikan pendidikan strata dua dan sisanya berpendidikan sarjana. Secara keseluruhan guru-guru mata pelajaran geografi pada SMAN di Palangka Raya sudah memenuhi ketentuan perundang-undangan. Guru geografi di SMAN Palangka Raya merupakan guru yang berpengalaman berdasarkan lama mengajar. Guru yang 
mengajar > 15 tahun ada sembilan orang. Guru dengan lama mengajar 5-10 tahun dan 10-15 tahun masingmasing tiga orang. Sisanya merupakan guru baru $(<5$ tahun mengajar).

Instrumen penelitian yang dikembangkan oleh (Riduwan, 2010) dengan beberapa modifikasi pada bagian identitas partisipan digunakan dalam penelitian ini. Instrumen ini mengukur IK guru berdasarkan empat dimensi, yaitu dukungan, persahabatan, keintiman, dan kooperatif yang dibagi menjadi 12 item. Sedangkan instrumen PTP memuat tiga dimensi pengukuran, yaitu: teknologi informasi dan komunikasi, media cetak, dan teknologi audio visual yang didistribusikan dalam 10 item. Adapun parameter KP diukur berdasarkan dua dimensi, yaitu proses belajar mengajar dan hasil belajar yang dijabarkan dalam 12 item. Instrumen penelitian diukur berdasarkan lima tanggapan dalam skala Likert. Reliabilitas masing-masing instrumen menunjukan konsistensi/keajegan yang tinggi $(\mathrm{rl}$ l $>0,700 ; \mathrm{r}$ tabel $>$ 0,497; $n=16$ ) dimana instrumen IK, PTP, dan KP berturut-turut memiliki nilai Alpha Cronbach sebagai berikut: $\mathrm{rl}$ I (IK) > 0,743; r I I (PTP) > 0,743; dan r I (KP) $>0,736$.

Deskripsi data persepsi IK guru, PTP, dan KP geografi disajikan dalam nilai persentase (Riduwan, 2004). Sedangkan klasifikasi ketiga peubah tersebut dikelompokan menjadi tiga tingkatan (Mangkuatmodjo, 1997). Analisis korelasi yang digunakan adalah analisis korelasi Spearman-rho. Analisis statistika ini mengukur asosiasi antara dua peubah diukur dengan skala ordinal sehingga obyek yang sedang di teliti dapat dirangking dalam dua seri urutan ranking (Ghozali, 2006). Perhitungan analisis korelasi Spearman-rho dilakukan dengan bantuan perangkat lunak SPSS versi 18.0. (Statistical Package for the Social Sciences, 2009).

\section{HASIL DAN PEMBAHASAN}

Secara umum IK (skor = 48-58; skala linkert $=5$; item $=12$ ) dan KP geografi (skor $=46-59$; skala linkert $=5$; item $=12$ ) yang dilakukan oleh partisipan penelitian menunjukan tingkatan yang tinggi (pada skala tiga). Begitu juga dengan PTP secara umum menunjukan tingkatan yang tinggi (skor $=38-48$; skala linkert $=5$; item $=10)$. Ringkasan klasifikasi persepsi guru geografi SMAN di Kota Palangka Raya tentang IK, PTP, dan KP yang mereka lakukan disajikan pada Tabel I.

Sebaran data untuk peubah IK, PTP, dan KP geografi disajikan dalam diagram pencar (Gambar I). Hubungan antara IK dengan KP menunjukan adanya hubungan positif tetapi kekuatan hubungannya rendah $(r=0,467)$ dan kebermaknaan hubungannya tidak penting $(P=$ 0,068). Namun, demikian hubungan antara PTP dengan KP menunjukan hubungan yang searah dan lebih erat $(r$ $>0,600$ ) dan hubungan ini secara statistika bermakna atau penting $(p=0,009)$.

Tabel I. Ringkasan deskripsi tingkatan IK, PTP, dan KP geografi yang dipersepsikan oleh guru partisipan

\begin{tabular}{|c|c|c|c|}
\hline \multirow{2}{*}{ Peubah } & \multicolumn{3}{|l|}{ Tingkatan } \\
\hline & Tinggi & Sedang & Rendah \\
\hline Iklim kerja & $16(100,0)$ & $0(0,0)$ & $0(0,0)$ \\
\hline $\begin{array}{l}\text { Teknologi } \\
\text { pembelajaran }\end{array}$ & I $5(93,8)$ & I $(6,3)$ & $0(0.0)$ \\
\hline $\begin{array}{l}\text { Kualitas } \\
\text { pembelajaran }\end{array}$ & $16(100,0)$ & $0(0,0)$ & $0(0.0)$ \\
\hline
\end{tabular}

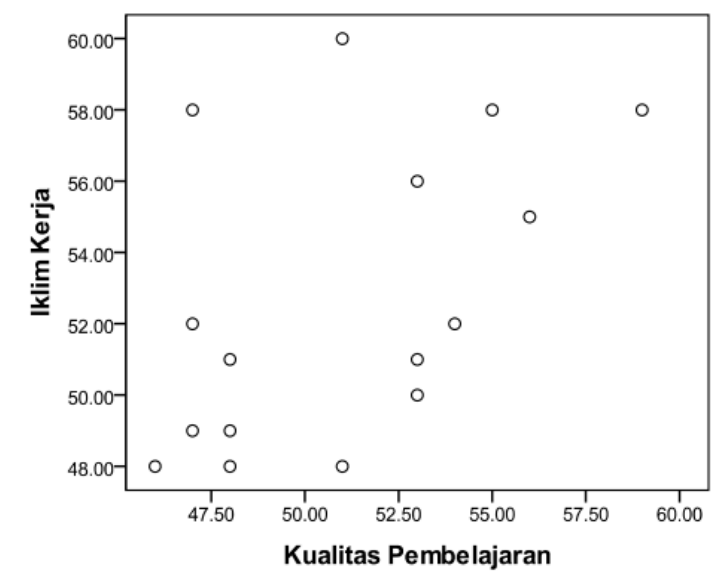

(a) 


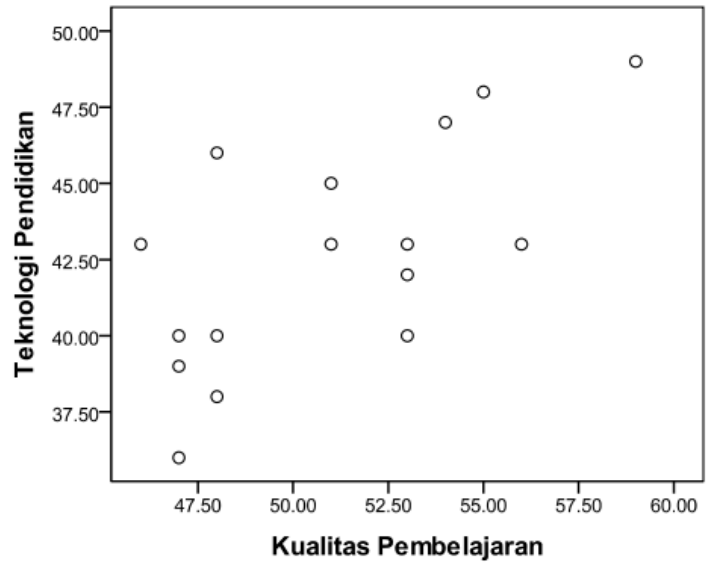

(b)

Gambar I. Diagram pencar yang terbentuk oleh masing-masing peubah. (a) IK dengan $\mathrm{KP}(r=0,467$; $\mathrm{P}$ $=0,068)$; (b) PTP dengan KP $(r=0,63 \mathrm{I} ; \mathrm{p}=0,009)$. $\mathrm{N}$ $=16$.

Sumber daya dalam organisasi atau lembaga pendidikan antara lain: manusia, sarana dan prasarana, biaya, teknologi dan informasi. Namun, sumberdaya manusia merupakan sumber daya organisasi pendidikan yang paling penting dalam mencapai keberhasilan (Sonedi, 2013; Fattah, 2013). Sumber daya manusia utama dalam organisasi atau sistem pendidikan adalah guru (Ismaniati, 20II). Guru merupakan kunci peningkatan mutu pendidikan. Guru bertanggung jawab untuk mengatur dan menciptakan suasana yang mendorong siswa untuk melaksanakan kegiatan-kegiatan di kelas. Peran guru sangat besar dalam pengelolaan kelas (Widiansyah, 2018; Ismaniati, 20 I I). Karakteristik guru yang berperan penting dengan kualitas pembelajaran antara lain, status sosial, ekonomi, tingkat pendidikan, dan pengalaman mengajar (Kompri, 20I5a).

Guru-guru yang menjadi partisipan penelitian merupakan guru-guru senior yang telah memiliki kematangan usia (>45 tahun) dan berpengalaman (>15 tahun). Karakter yang kuat dan kemampuan mengelola kegiatan belajar-mengajar dibentuk dari kematangan usia dan pengalaman mengajar. Lebih dari separuh partisipan ditempatkan di sekolah-sekolah unggulan dan lama karena kematangan usia dan pengalaman kerja mereka. Kelompok guru senior umumnya memiliki pengalaman dan wawasan yang luas sebagai seorang pendidik (Hermino \& Luangsithydeth, 2013).

Kinerja guru sangat dipengaruhi oleh pengalaman mengajar guru. Pengalaman mengajar yang diperoleh oleh guru akan membentuk kematangan dan kemantapan perilaku guru. Guru yang berpengalaman diharapkan akan memiliki kematangan pribadi dalam menjalankan tugas-tugas yang dipercayakan kepadanya. Guru yang berhasil menjalankan tugas sebagai guru maka kualitas pembelajaran yang dilakukannya akan makin meningkat (Sonedi et al., 2018). Suryani (201I) menjelaskan bahwa pengalaman adalah pekerjaan yang menghasilkan perubahan ke arah kematangan tingkah laku, pertambahan pengertian dan pengayaan informasi. Perubahan ke arah yang baik dapat meningkatkan kinerja. Sedangkan, puncak kesuksesan dan kematangan karir guru biasanya diperoleh pada rentang usia 35 tahun sampai 46 tahun.

Tingkat pendidikan partisipan juga menunjukkan tingkatan yang baik (telah menyelesaikan pendidikan sarjana), bahkan ada beberapa guru telah menyelesaikan pendidikan pada jenjang yang lebih tinggi (pendidikan pascasarjana). Ini membuktikan bahwa guru-guru yang menjadi partisipan penelitian merupakan guru yang berkualitas sehingga keberadaan mereka berperan dalam peningkatan kualitas pembelajaran. Guru yang unggul ditandai dengan kemampuan intelektual yang tinggi. Kemampuan intelektual diperoleh melalui pendidikan dan pelatihan serta pengalaman kerja. Perilaku profesional guru salah satunya dipengaruhi oleh tingkat pendidikan. Kualifikasi akademik pendidikan yang memadai merupakan sebuah prasyarat mutlak bagi seorang guru agar dapat melaksanakan tugasnya dengan baik. Kualifikasi akademik akan mempengaruhi bagaimana dia berperilaku dalam melaksanakan proses pembelajaran. Pendidikan akademik yang tinggi dan terstandard maka pelaksanaan pembelajaran yang dilakukan oleh guru di kelas makin baik (Iskarim, 2013). 
Namun demikian, secara umum faktor-faktor yang menentukan kinerja guru adalah faktor-faktor dari dalam dan faktor dari luar. Faktor-faktor dari dalam antara lain: I) kemampuan atau kompetensi guru; 2) faktor komitmen kinerja guru; 3) faktor perilaku guru; 4) faktor sikap; 5) faktor intelegensi guru; dan 6) faktor kecerdasan emosional guru. Sedangkan, faktor-faktor dari luar, antara lain: I) gaya kepemimpinan kepala sekolah; 2) supervisi dan pengawasan; 3) iklim kerja; 4) faktor sarana dan prasarana; dan 5) faktor budaya kerja (Sonedi et al., 2018; Suryani, 20I I).

Guru yang baik akan selalu meningkatkan kemampuannya secara profesional. (Kompri, 2015a). Komitmen guru untuk meningkatkan proses pembelajaran dapat dilakukan dengan lima cara, yaitu: I) peningkatan profesionalitas yang melekat pada dirinya secara dedikatif dan berkomitmen kepada mutu proses dan hasil belajar; 2) meningkatkan penguasaan ilmu dan mampu mengembangkan serta menjelaskan fungsi dalam kehidupan, menjelaskan dimensi teoritis dan praktisnya atau sekaligus melakukan transfer ilmu pengetahuan dan internalisasi serta amaliah; 3) mendidik dan menyiapkan peserta didik agar mampu berkreasi, mampu mengatur dan memelihara hasil kreasinya, serta menjadi model dan panutan atau teladan; 4) memiliki kepekaan intelektual dan informasi serta memperbaharui pengetahuan dan keterampilan secara berkelanjutan sehingga dapat ditransformasikan kepada peserta didiknya; dan 4) mampu bertanggung jawab dalam membangun peradaban yang berkualitas di masa akan datang (Muhaimin, 2003).

Iklim sekolah yang baik merupakan salah satu dari karakteristik sekolah yang efektif. IK yang baik adalah iklim atau suasana kondusif yang tercipta di dalam sekolah akibat pengaruh perilaku komponen sekolah dalam interaksi belajar mengajar maupun manajerial yang bersifat terbuka, kekeluargaan, komunikatif, memiliki otonomi, aman, tenteram, tertib aturan, dan tertib, serta bekerja dengan penuh tanggung jawab. IK yang kondusif dapat dicapai melalui manajemen dan gaya kepemimpinan kepala sekolah yang efektif serta melibatkan dan bekerja sama dengan semua pemangku kepentingan seperti guru, pegawai, komite sekolah dan siswa (Kompri, 20I5a). IK yang sehat (nyaman dan menyenangkan) akan membuat guru bekerja dengan leluasa dan menumbuhkan motivasi belajar siswa dalam kegiatan belajar mengajar. Sehingga kualitas pengajaran semakin meningkat, siswa dan guru memanfaatkan sumber belajar dan fasilitas belajar sekolah oleh secara optimal (Sagala, 2009).

Namun demikian, dalam penelitian ini IK menunjukkan hubungan yang tidak bermakna $(r=0,467 ; p=0,068)$. $\mathrm{Hal}$ ini mungkin disebabkan oleh faktor guru yang merupakan guru senior dan fasilitas sekolah (khususnya sekolah unggulan dan lama). Di mana hampir separuh dari responden penelitian ini adalah guru yang berasal dari sekolah unggulan dan lama. Hal ini sesuai dengan pendapat Novauli (2015) yang menyatakan bahwa mutu pembelajaran sangat ditentukan oleh kualitas sekolah, kapasitas dan kompetensi guru, serta manajemen pendidikan. Lebih lanjut, proses belajar mengajar erat kaitannya dengan lingkungan atau suasana di mana proses belajar mengajar berlangsung. Iklim kerja bukanlah faktor tunggal yang mempengaruhi KP. Ada beberapa faktor lain yang mempengaruhi KP, yaitu gaya belajar peserta didik, kualitas dan kreativitas guru, dan fasilitas belajar yang tersedia (Hadiyanto, 2004), dan kinerja kepala sekolah, serta dukungan orang tua atau lingkungan (Sonedi et al., 2018; Suryani, 201 I).

Setiap lembaga pendidikan di era modern sangat tergantung dengan kehadiran fasilitas. Peningkatan mutu pendidikan bisa dilakukan dengan melakukan pembenahan fasilitas. Fasilitas sangat mendukung dan memperlancar proses pendidikan. Fasilitas merupakan syarat mutlak bagi suatu lembaga pendidikan. Pencapaian tujuan pendidikan harus memperhatikan kualitas dan kuantitas fasilitas yang terkini (Kompri, 2015a). 
Partisipan penelitian telah memanfaatkan teknologi pembelajaran yang ada untuk mendukung proses belajar mengajar di sekolah (Tabel I). PTP dalam kegiatan belajar mengajar dipengaruhi oleh faktor sosial historis dari guru yang bersangkutan. Faktor pertama adalah kemampuan dan penguasaan teknik baik keterampilan maupun kompetensis guru terhadap teknologi informasi dan komunikasi (TIK) atau literasi teknologi. Faktor kedua, latar belakang sosial guru. Guru-guru dengan status sosial menengah ke atas lebih bisa beradaptasi dengan TIK dibandingkan dengan golongan menengah ke bawah. Faktor ketiga, faktor historis, guru-guru yang sudah terbiasa menggunakan dengan media pembelajaran konvensional cenderung menolak integrasi teknologi pendidikan dalam proses belajar mengajar. Namun demikian, ada faktor-faktor lain yang mempengaruhi penggunaan teknologi pembelajaran antara lain: politik komunitas (kepemimpinan kepala sekolah) serta faktor ekonomi (terkait dengan kemampuan sekolah untuk menyediakan sarana dan prasarana pendidikan berbasis TIK (Suratman, 20I0).

Pemanfaatan teknologi pembelajaran memiliki hubungan positif yang kuat dan bermakna dengan $\mathrm{KP}(r=0,63 \mathrm{I}$; $\mathrm{P}$ $=0,009)$. Hasil penelitian ini sejalan dengan penelitian yang dilakukan oleh Triyanto et al. (2013) yang menyatakan bahwa pemanfaatan teknologi pendidikan/pembelajaran memberikan dampak positif dalam mendukung proses belajar-mengajar. Teknologi pembelajaran berperan dalam membelajarkan peserta didik, memfasilitasi belajar dan meningkatkan kinerja peserta didik, memudahkan proses belajar, memecahkan masalah belajar yang dihadapi, membuat peserta didik belajar lebih baik, yaitu lebih cepat, menyenangkan, menarik, memotivasi, dan efektif, efisien serta relevan (Suprapto, 2006; Ismaniati, 20 I I; Triyanto et al., 20।3; Kompri 20I5b).

Namun demikian, teknologi pembelajaran (pembelajaran berbasis komputer dan internet) memiliki kelemahan, antara lain: I) komputer/internet cenderung mengisolasi; 2) komputer/internet cenderung membuat orang pasif secara fisik; 3) komputer/internet cenderung hanya cocok untuk sayu gaya belajar (auditori dan visual) sedangkan pembelajaran kinestesis cenderung menganggap pembelajaran berbasis komputer/internet itu lamban, membosankan, dan tidak efektif; dan 4) komputer/internet cenderung berdasarkan media dan bukan pengalaman (Kompri, 20I5b).

Hasil penelitian ini membuktikan bahwa terdapat hubungan yang erat antara PTP dengan KP. Oleh karena itu implikasi penelitian ini adalah Oleh karena itu kepada para guru untuk selalu meningkatkan literasi teknologi pendidikan dan menerapkan kemampuannya dalam proses belajar-mengajar. Fasilitas teknologi pembelajaran yang sudah tersedia di sekolah untuk dimanfaatkan secara optimal dalam proses belajar mengajar di kelas. Sedangkan, kepala sekolah dapat memimpin dan mengorganisasi proses belajar mengajar dan memotivasi guru-guru meningkatkan pengetahuan dan keterampilan untuk menggunakan teknologi pembelajaran dalam proses belajar mengajar. Di samping itu, memfasilitasi penyediaan dan melengkapi teknologi pembelajaran yang mendukung proses pembelajaran di sekolah secara bertahap dan berkelanjutan.

\section{KESIMPULAN}

Iklim kerja di sekolah yang disigi cenderung tidak memiliki hubungan yang erat dengan KP geografi. Namun, dalam penelitian ini membuktikan bahwa PTP cenderung berhubungan erat dengan KP geografi pada SMAN di Kota Palangka Raya. PTP yang tepat dan menarik dapat membantu peserta didik untuk memahami materi pembelajaran yang disampaikan oleh guru sehingga KP semakin baik. Penelitian lebih lanjut dengan partisipan yang lebih banyak akan mendukung penelitian ini. 


\section{REFERENSI}

Anshori, S. 2017. Pemanfaatan TIK Sebagai Sumber dan Media Pembelajaran di Sekolah. Civic-Culture: Jurnal Ilmu Pendidikan PKN dan Sosial Budaya, I, 10-20.

Esi, Purwaningsih, E., \& Okianna. 2016. Peranan Guru Sebagai Fasilitator dan Motivator dalam Meningkatkan Hasil Belajar di Kelas XI SMK. Jurnal Pendidikan dan Pembelajaran, 5, I-I4.

Fattah, N. 2013. Landasan Manajemen Pendidikan. Cetakan ke-13. Bandung: Remaja Rosda Karya.

Ghozali, I. 2006. Statistik Non Parametik: Teori \& Aplikasi dengan Program SPSS. Semarang: Badan Penerbit UNDIP.

Hadiyanto. 2004. Mencari Sosok Desentralisasi Manajemen Pendidikan di Indonesia. Jakarta: Rineka Cipta.

Hermino, A. \& Luangsithydeth, V. 2013. Pendidikan Karakter Dalam Perspektif Psikologis Siswa Sekolah Menengah Pertama di Era Globalisasi dan Multikultural. Jurnal Manajemen Pendidikan, 24, I|4-I 24.

Iskarim, M. 2013. Menjadi Guru: Antara Realitas dan Idealitas. Forum Tarbiyah, II, 95-I I5.

Ismaniati, C. 20II. Aplikasi Teknologi Pendidikan bersama Pendidikan Profesional: Suatu Strategi Inovatif Peningkatan Mutu Pendidikan. Dinamika Pendidikan, I8, I-I2.

Kompri. 20I5a. Manajemen Pendidikan I. Bandung: Alfabeta.

Kompri. 20I5b. Manajemen Pendidikan 2. Bandung: Alfabeta.

Mangkuatmodjo, S. 1997. Pengantar Statistik. Jakarta: Rineka Cipta.

Muhaimin. 2003. Wacana Pengembangan Pendidikan Islam. Yogyakarta: Pustaka Pelajar.

Munfarijah, S. 20I5. Upaya Meningkatkan Motivasi Kerja dan Kreativitas Dalam Kepemimpinan PAUD. Jurnal Kependidikan, 3, I63-182.

Novauli, F.M. 2015. Kompetensi Guru Dalam Peningkatan Prestasi Belajar Pada SMP Negeri dalam Kota Banda Aceh. Jurnal Administrasi Pendidikan, 3, 45-67.
Nurbudiyani, I. 2013. Pelaksanaan Pengukuran Ranah Kognitif, Afektif, Dan Psikomotor Pada Mata Pelajaran IPS Kelas III SD Muhammadiyah Palangkaraya. Anterior Jurnal, I3, 88-93.

Riduwan. 2004. Metode dan Teknik Menyusun Tesis. Bandung: Alfabeta.

Riduwan. 2010. Skala Pengukur Variabel-Variabel Penelitian. Jakarta: Alfabeta.

Rohmawati, A. 2015. Efektivitas Pembelajaran. Jurnal Pendidikan Usia Dini, 9, 2015.

Sagala, S. 2009. Kemampuan Profesional Guru dan Tenaga Kependidikan. Bandung: Alfabeta.

Sonedi, S., Sholihah, T., \& Dihasbi, D. 2018. Peran Kepemimpinan Kepala Sekolah dalam Meningkatkan Kinerja Guru. Anterior Jurnal, 18, 13-22.

Sonedi, S. 2013. Keefektifan Organisasi Perguruan Tinggi (Studi Kasus Pada Universitas Muhammadiyah Palangkaraya). Anterior Jurnal, I3, 106-121.

Statistical Package for the Social Sciences. 2009. PASW Statistics for Windows, Version 18.0. Chicago: SPSS Inc.

Suniati, S. 2014. Hubungan Gaya Kepemimpinan Kepala Sekolah Dengan Efektivitas Sekolah Menengah Atas Negeri Se-Kota Palangka Raya. Anterior Jurnal, I4, I I0-I I8.

Suprapto. 2006. Peningkatan Kualitas Pendidikan melalui Media Pembelajaran Menggunakan Teknologi Informasi di Sekolah. Jurnal Ekonomi Pendidikan, 3, 34-4I.

Suratman, B. 2010. Kompetensi Manajerial Kepala Sekolah, Ketersediaan Sarana Prasarana, Kapabilitas Mengajar Guru, dan Dukungan Orang Tua, Kaitannya dengan Prestasi Belajar Siswa SMP Negeri di Kota Surabaya. Jurnal Pendidikan dan Pembelajaran, 17, 89-97.

Suryani, N.N. 20II. Kontribusi Sikap Profesional Seorang Guru, Iklim Kerja Sekolah, dan Pengalaman Kinerja Guru terhadap Kinerja Guru pada SMA Negeri di Kabupaten Badung. Jurnal Ilmiah Pendidikan dan Pembelajaran Ganesha, 7, I-I3.

Triyanto, E., Anitah, S., \& Suryani, N. 2013. Peran Kepemimpinan Kepala Sekolah dalam Pemanfaatan Media Pembelajaran sebagai Upaya Peningkatan Kualitas Proses 
Pembelajaran. Jurnal Teknologi Pendidikan, I, 226-238.

Widiansyah, A. 2018. Peranan Sumber Daya Pendidikan Sebagai Faktor Penentu Dalam Manajemen Sistem Pendidikan. Cakrawala: Jurnal Humaniora Bina Sarana Informatika, 18, 229234. 